\title{
Oil spill detection in the east of Sri Lanka with Sentinel-1 SAR
}

\author{
$W$. Kamal M. Mahindapala ${ }^{1^{*}}$ \\ ${ }^{1}$ Arthur C Clarke Institute for Modern Technologies, Moratuwa, Sri Lanka.
}

\begin{abstract}
In September 2020, two major fires broke out in a large crude oil tanker in Sri Lanka's maritime zones. An island with a vast sea area in the Indian Ocean, Sri Lanka, is prone to vessel sourced pollution. Crude oil can have a damaging impact on the environment, and therefore tracking the spill in the water is essential. Spaceborne sensors support monitoring oil pollution; however, optical sensors need clear skies for observation. The detection of pollution caused by vessels; in Sri Lanka's maritime zones has previously been investigated by the author. This study examines the data collected by the Sentinel-1 satellite, whose sensing corresponds to the oil spill event, manually and using algorithms to detect the presence of oil spills. Two detected oil spill areas were measured to be $0.6 \mathrm{~km}$ and $1.4 \mathrm{~km}$ long. Further, in this study, the SAR sensor's vertical signal transmission and reception mode produced acceptable results in detecting the spills and the vessel. Sentinel-1 SAR data is essential, in this case, to detect the presence of the oil spills and the vessels.
\end{abstract}

\section{Introduction}

This study has been motivated by an interest in the application of Earth Observation (EO) Copernicus Sentinel-1 Synthetic Aperture Radar (SAR) data in the detection of possible marine pollution by the tanker called "New Diamond," which caught fire, on 03 September 2020, in the east of Sri Lanka. Also, the detection of pollution caused by vessels; in Sri Lanka's maritime zones has previously been investigated [1].

a

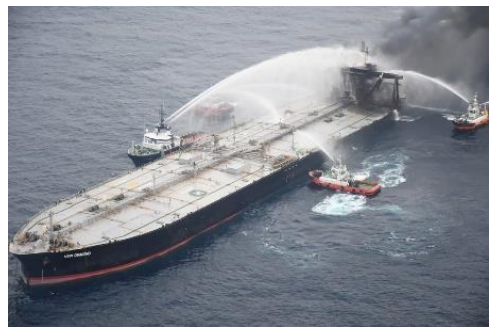

b

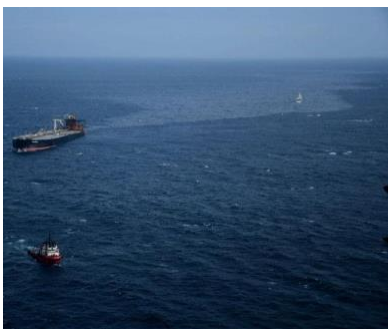

Fig. 1. (a). Intensified efforts to put an end to a new fire on the oil tanker off Sri Lanka's coast on September 8, 2020; 2 days after the previous 3-day fire was doused (Sri Lankan Air Force via AP) [2]; (b) The photograph, by Sri Lanka Air Force, after the fires onboard had been controlled [3]

* Corresponding author:mhndpl@yahoo.com 
On 03 September 2020, a fire broke out in "New Diamond," a $330 \mathrm{~m}$ tanker, which is carrying crude oil about 38 NM off Sangamankanda in Sri Lanka's east coast and, 02 days after the fire was extinguished, a new fire broke out (Fig. 1. (a)). It was drifting towards the shore, therefore; it was towed further into the deep sea. An aircraft was deployed to spray a chemical on the oil patch that the tanker had left. By 10 September 2020, the fire was extinguished (Fig. 1. (b)). According to the disaster management team, crude oil storage is safe, and the tanker is located about $50 \mathrm{NM}$ off the east coast.

Leakages, bilge-water, and other wastes produced due to an accident or deliberate act pollute the sea. A tanker is a ship designed to transport liquid cargo without using barrels or containers. Ultra-Large Crude Carriers (ULCCs) have a length of $415 \mathrm{~m}$, and ULCCs carry 2 million to 3 million barrels of crude oil. Very Large Crude Carriers (VLCCs) transport 2 million barrels of crude oil and have a length of $330 \mathrm{~m}$. ULCCs and VLCCs, frequently called supertankers, with large diesel engines capable of delivering power exceeding $100,000 \mathrm{hp}$, always carry crude oil. These tankers caused considerable damage in the past [4].

An island with a vast sea area in the Indian Ocean, Sri Lanka, is prone to vessel sourced pollution. A high risk of oil spill events exists due to the marine traffic generated by tankers and other vessel types within and close to the Exclusive Economic Zone (EEZ), pumping oil imported to the country, and oil tanks (Sri Lanka's east), and the vessels call on the local ports. Vessel accidents occurred in the southern sea area, an oil spill along the western coast, and an oil pipeline burst; are among the recent events. Oil spills can create an irreversible impact on the species in the island's maritime zones and lagoons. Sri Lanka's land and the maritime zones will be vulnerable to oil spills if there is no intense monitoring to prevent or mitigate the impact. Vessels escape detection, and vessel sourced pollution will continue.

Existing spaceborne sensors support monitoring the pollution in the vast sea area. Sensors on satellites are sensitive to different wavelengths from optical to microwave. Therefore, they are capable of detecting features that a naked human eye cannot. However, EO data is not always available due to satellites' revisit times. Optical sensors need clear skies for observation, and also optical EO images cannot be collected at low visibility times. Therefore, optical sensors have a very low probability of observing a marine oil spill. SAR can penetrate clouds, and the data recorded during the day or at low visibility times by SAR satellites are useful. Therefore, SAR data can be applied to detect marine oil pollution. Copernicus Sentinel 1A and 1B satellites reduce revisit time, and the European Space Agency (ESA) has provided open access to data and software.

a

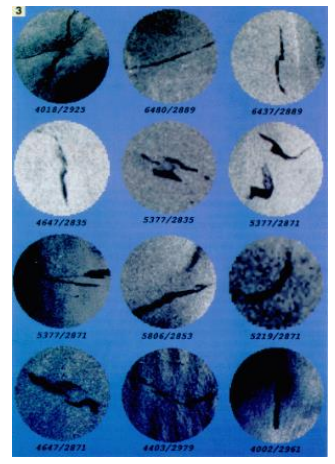

b

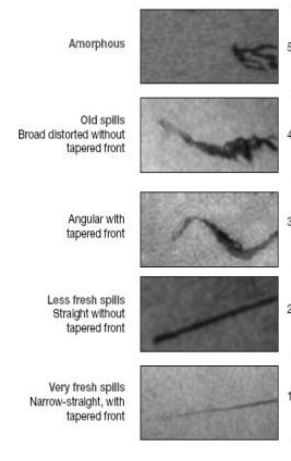

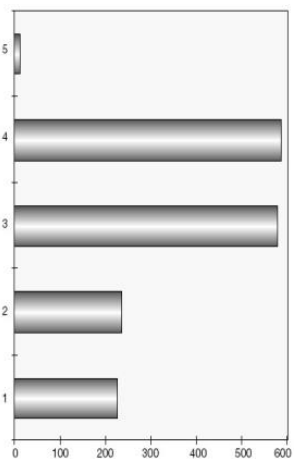

Fig. 2. (a) Typical shapes of detected spills on ERS-1 SAR [5]; (b) Detected spills classified in terms of their shapes [6] 
SAR sensor observes variations on the ocean surface, caused by either a human-made or a natural event. Spill shapes are shown in Fig. 2. (a), and most of the detected oil spill shapes are leakages or bilge-water. However, due to complicated scenarios, identification of the nature of the detected oil spill depends on the interpreter's experience. 1638 number of detected oil spills and five categories identified by classifying them according to the shapes shown in Fig. 2. (b).

Computer algorithms facilitate the detection of vessels and oil spills without heavily depending on an experienced interpreter. Crisp [7] states, application of target detection algorithms depends on SAR image resolution, complexity, intensity, amplitude, and the number of looks. The most common target detection algorithms used in SAR data are the Adaptive Threshold (AT) algorithms. The two-parameter Constant False Alarm Rate (CFAR) detector and the cell averaging CFAR detector are the most common AT algorithms. Discrimination is used to reduce false alarms among the candidate targets on the portion of the image that is already identified by pre-screening.

This study aims at detecting the oil spill caused by the "New Diamond" tanker on Sri Lanka's east coast in September 2020; with SAR data. The introduction section includes the background and the technology used to achieve the objectives of this study. Section 2 introduces the methods used for spills and tanker detection. The results are presented in section 3 , and the references follow the conclusion section.

\section{Method}

SAR sensor's VV polarization (vertical signal transmission and reception) mode is used for oil spill detection. The SAR imagery acquired at VV polarization is sensitive to the sea surface roughness. Suppression of the capillary waves by an oil spill reduces radar backscatter, and the sea surface appears darker in the image. VV polarization is better than other polarizations; for spill detection [8]. Rough sea surfaces appear brighter in SAR images. Wind and ship wake create a rough surface. Surface roughness, which is needed by the SAR sensors, is generated by the wind speeds between 3 and $12 \mathrm{~m} / \mathrm{sec}$ [9]. SAR image acquired at $\mathrm{VH}$ polarization is more suitable for ship detection as the resulting contrast between sea-water and ships is significant [10]. Sentinel 1 GRD DV (dual VV+VH polarization) data, processed by ESA, returned by the search on the Copernicus open access hub are used in this study (Table 1).

Table 1. Details of Sentinel 1 (12-day), $5 \mathrm{~m}$ x $20 \mathrm{~m}$ ground resolution data

\begin{tabular}{llll}
\hline Dataset \& Type & Date & $\begin{array}{l}\text { Sensing: HHMMSS } \\
\text { (UTC) }\end{array}$ & $\begin{array}{l}\text { Ingestion: } \\
\text { HHMMSS (UTC) }\end{array}$ \\
\hline S1A_IW_GRDH_1SDV & $2020-09-12$ & $00: 17: 06-00: 17: 42$ & 2020-09-12 / 03:47 \\
\hline
\end{tabular}

Sentinel Application Platform (SNAP) algorithms were applied to visualize the SAR data, process the data, and visualize the results. Possible oil spill spots that are darker than the surrounding area of the SAR image were located. Adaptive Threshold algorithm detects dark spots, e.g., oil spill. Different values were used for background window size and threshold shift $(\mathrm{dB})$ parameters and visualized the dark spots extracted. SNAP's ocean object detector includes pre-screening and discrimination operations. It applies the twoparameter constant false alarm rate (CFAR) detector for pre-screening to detect unusually bright spots. It can be seen (Fig. 1. (b)) that the tanker is either moving slowly or stationary, therefore, ship wakes are not generated. 


\section{Results and discussions}

The Sentinel 1A SAR, VV, and VH polarization images, which cover the study area (Fig. 3. (a)), were explored manually with the SNAP software to identify dark spots. During the initial exploration, three dark lines were visible with eight bright spots close to one of the dark lines in the VV polarization mode (Fig. 3. (b)).

a

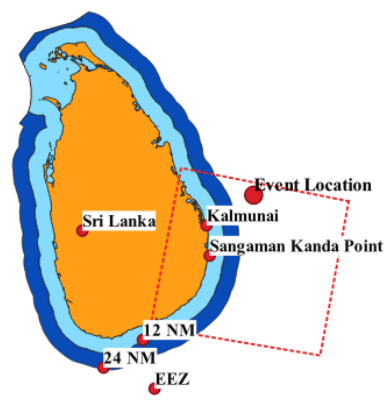

b

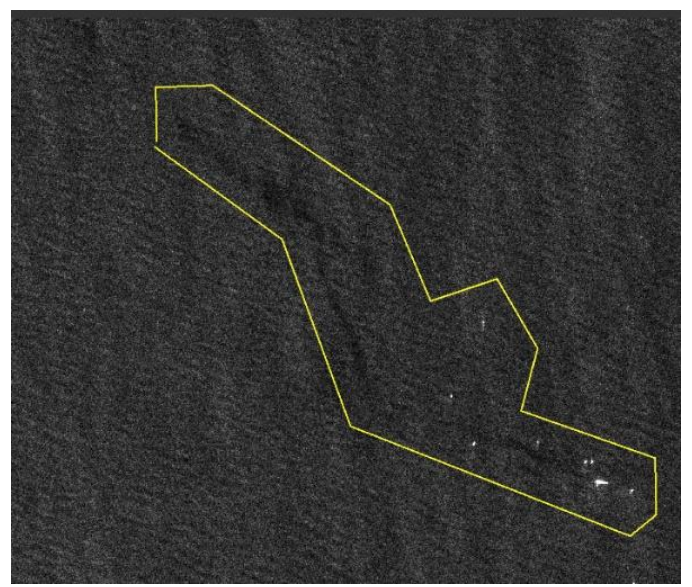

Fig. 3. (a) Possible oil spills are expected to be detected within the event location, which is in the east of Sri Lanka's EEZ. Also, the location is further away from the $24 \mathrm{NM}$ zone. The dotted line marks the Sentinel 1 A image, covering the study area; (b) Image in VV polarization mode shows three dark lines with eight bright spots inside the polygon. Close to the last dark line, the bright spots can be seen
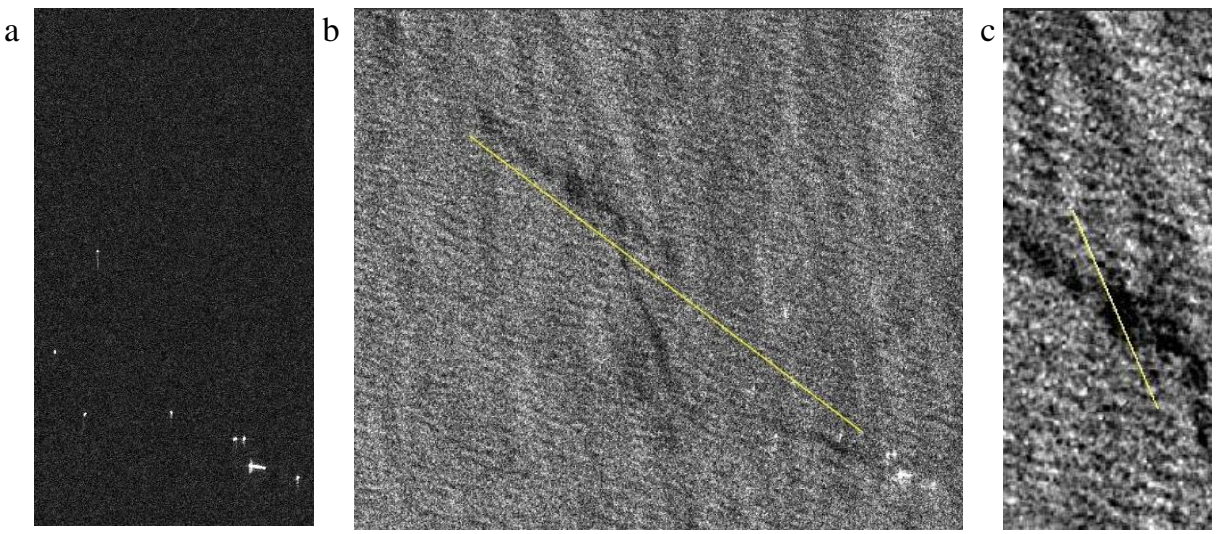

Fig. 4. (a) Eight bright spots in VH mode; (b) Three dark lines $14 \mathrm{~km}$ long along the straight line in VV polarization mode; (c) Dark spots in speckle filtered image.

Subsets of data, which contain the dark lines and the bright spots, were extracted and visualized. The dark lines are visible in the VV polarization mode, and the lines cover an area of $14 \mathrm{~km}$ long (Fig. 4. (b)), but VH mode only has the bright spots (Fig. 4. (a)). Further, the dark lines are visible clearly in the speckle filtered VV mode data subset (Fig. 4. (c)). The profile plot indicates that Fig. 4 (c) has some spots with low reflectance (Fig. 5). Therefore, the data processed with the SNAP. The VV polarization mode subset data processing, using the parameters; threshold shifts $2.5 \mathrm{~dB}$ and background window size 350 
pixels; show two detected oil spill areas measured to be $0.6 \mathrm{~km}$ and $1.4 \mathrm{~km}$ long. They are 9 km apart (Fig. 6).

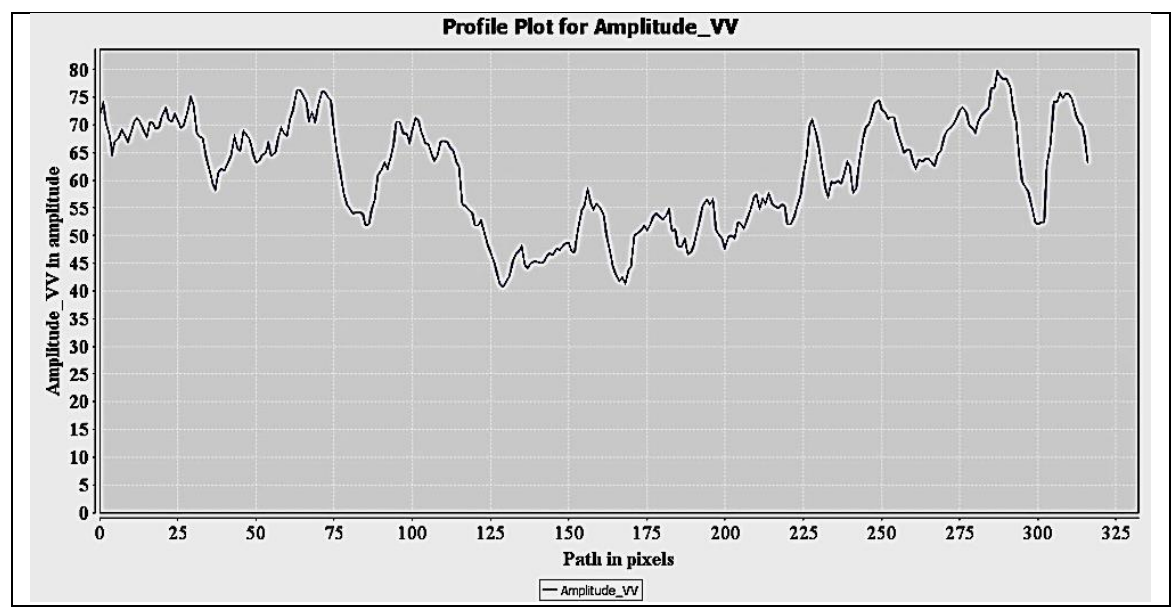

Fig. 5. Profile plot indicates spots (along the path, the straight line in Fig. 4. (c)) with low reflectance

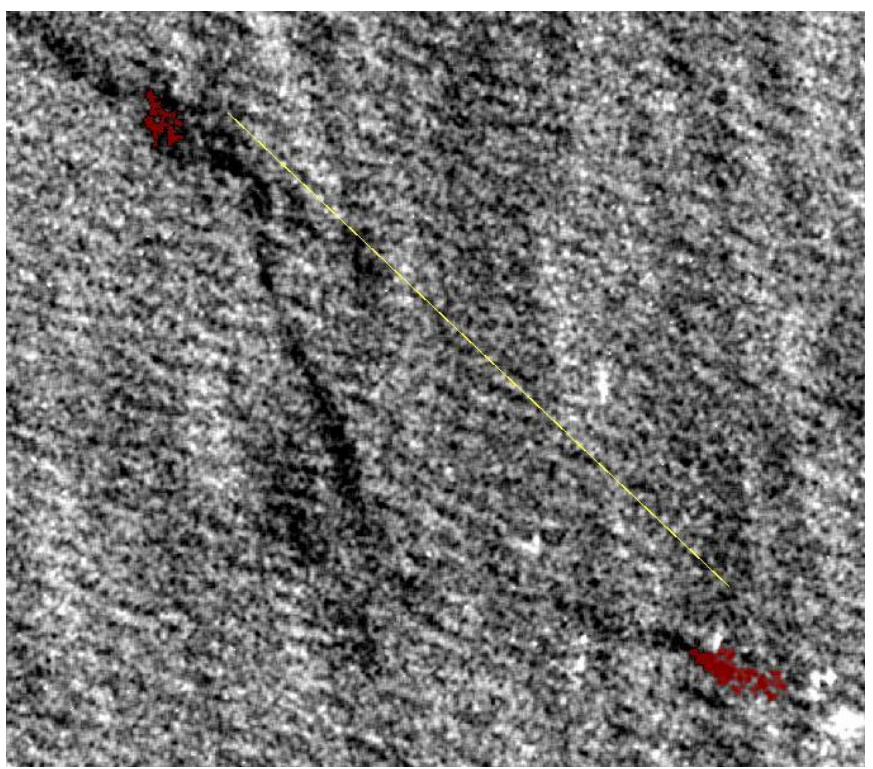

Fig. 6. The two detected oil spill areas in red color, measured to be $0.6 \mathrm{~km}$ (top) and $1.4 \mathrm{~km}$ (bottom) long. The straight-line measured distance is $9 \mathrm{~km}$.

Results of the data subsets processing, with SNAP's ocean object detector, using the parameters; target window size $400 \mathrm{~m}$ and minimum target size $320 \mathrm{~m}$; show one detected bright spot with a red circle which is close to the other bright spots and at the end of the last dark line, in the VV polarization mode (Fig. 7. (a)). In the VH polarization mode, dark lines are not visible. One detected bright spot is marked with a red circle (Fig. 7. (b)). Fig. 7. (c) shows the image (Fig. 7. (a)) with ellipsoid correction (geolocation-grid), EPSG:5234 Kandawala / Sri Lanka Grid. 
a

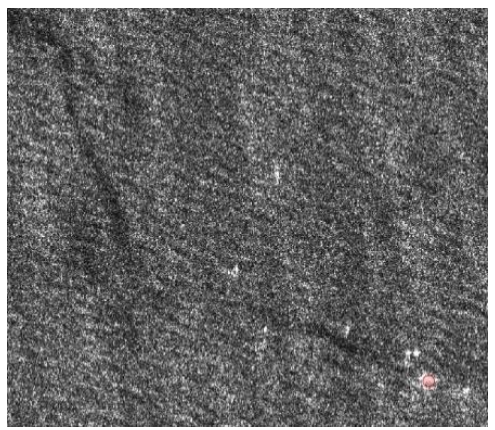

$\mathrm{b}$

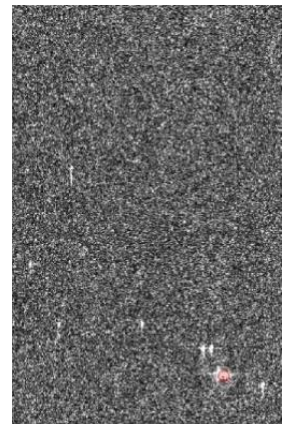

$\mathrm{c}$

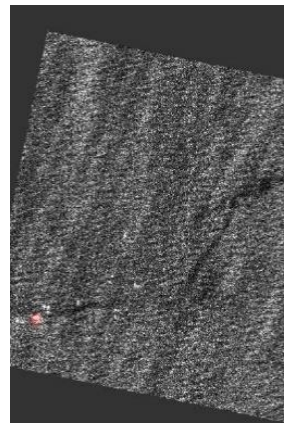

Fig. 7. (a) Shows the vessel detected in the VV polarization mode. The dark lines and bright spots are visible. One detected bright spot is marked with a red circle; (b) Shows the vessel detected in the VH polarization mode. The dark lines are not visible. The bright spots are visible, and one detected bright spot is marked with a red circle; (c) Ellipsoid correction (geolocation-grid) applied to Fig. 7. (a)

\section{Conclusion}

It can be seen that the results generated by the SAR data processing and the images above are related. The SAR data detected the "New Diamond" tanker and the oil spills; when compared with the visuals (Fig. 1. (b)). The oil spills detected can be seen on the dark lines. Therefore, the tanker has moved, and the dark lines might indicate the path. According to the Fig. 7. (c), by 5:47:06 AM on 12 September (local time), the tanker has moved towards Sri Lanka. Sentinel-1 SAR data is essential and the ingestion of the SAR data is done in a few hours. This is very important to respond to an oil spill event early. The SAR GRDH data tile covers the territorial sea and the contiguous zone. It is also useful in detecting the vessels and oil spills in the exclusive economic zone.

\section{Acknowledgements}

The author would like to thank the European Space Agency (ESA) to provide open access to the Sentinel-1 data and the software. Also, the author would like to thank the School of Environmental Science, Universitas Indonesia, Jakarta.

\section{References}

1. W. K. M. Mahindapala, IOP Conf. Ser.: Earth Environ. Sci. 509 012035, (2020) Retrieved from https://doi.org/10.1088/1755-1315/509/1/012035

2. B. Mallawarachi, Diesel fuel found in ocean near Sri Lanka oil tanker fire. AP News, Top Stories, (2020, September 8) Retrieved from https://apnews.com/922455c6fbed4a40a066d7e093dcf8bb

3. Fire on oil tanker controlled, Daily Mirror, (2020, September 9) Retrieved from http://www.dailymirror.lk/caption_story/Fire-on-oil-tanker-controlled/110-195522

4. Tanker, In Encyclopædia Britannica. (2018, October 31) Retrieved from https://www.britannica.com/technology/tanker

5. P. Pavlakis, A. Sieber, S. Alexandry, Monitoring oil-spill pollution in the Mediterranean with ERS SAR. ESA Earth Observation Quarterly, 52 (1996) Retrieved from https://www.researchgate.net/publication/269762055 
6. P. Pavlakis, D. Tarchi, A. J. Sieber, On the monitoring of illicit vessel discharges a reconnaissance study in the Mediterranean Sea (2001) Retrieved from https://ec.europa.eu/echo/files/civil_protection/civil/marin/reports_publications/jrc_illi cit_study.pdf

7. D. J. Crisp, The state-of-the-art in ship detection in synthetic aperture radar imagery. Edinburgh, Australia: DSTO Information Sciences Laboratory (2004)

8. Natural Resources Canada, Oil Slick Detection. Retrieved from https://www.nrcan.gc.ca/earth-sciences/geomatics/satellite-imagery-airphotos/satellite-imagery-products/educational-resources/9525 (2015, November 24)

9. D. A. Gagliardini, P. C. Colón, Ocean feature detection using microwave backscatter and sun glint observations. Gayana, 68(2), 180-185. (2004) Retrieved from https://scielo.conicyt.cl/scielo.php?script=sci_arttext\&pid=S0717-65382004000200033

10. A. Chybicki, L. Markiewicz, Coastal zone monitoring using sentinel-1 sar polarimetry data. Hydroacoustics, 18, 25-32 (2015) Retrieved from http://yadda.icm.edu.pl/yadda/element/bwmeta1 .element.baztech-f52a753d-4286-4f0baba1-726ef77308eb/c/Hybicki_2CMarkiewicz_hydroacoustics-vol18.pdf 